\title{
SCIDoC
}

International Journal of Dentistry and Oral Science (IJDOS)

ISSN: 2377-8075

\section{Evaluation of Various Positions on the Ovine Pelvis for Dental Implant Research}

Research Article

Hendrik Kloppers*

Registrar, Department of Maxillo-Facial and Oral Surgery, University of Pretoria, South Africa.

\section{Abstract}

Aims: An ex vivo and in vivo study to determine various positions in the ovine pelvis to evaluate dental implant placement.

Settings and Design: - A novel, unique surgical dissection was described as the caudal roll-up technique and was utilized to obtain maximal exposure to the Linea Glutea, with the least morbidity.

- Insertion torque (IT) of osseo-integrated dental implants was measured at predetermined positions described as A-F along the ovine linea glutea.

- The amount of outer cortical bone was measured at predetermined sections A-F on harvested ovine pelvi, to coincide with the implant positions as placed.

Statistical analysis used: Descriptive Study.

Intraoral dental implant research in animals is challenging, owing in particular to different tooth morphology. One of the most challenging problems with intraoral implant research in animals is an infection form contaminated oral cavity, which is evident in intraoral research related to pigs and dogs [8]. Intraoral dental implant studies by Vlaminck confirmed that the specific oral biomechanics inherent to a sheep's constant ruminant activity accounted for high degrees of implant failures $[13,25]$. A novel, unique surgical dissection was described as the caudal roll-up technique and was utilized to obtain maximal exposure to the Linea Glutea, with the least morbidity. Data collected concerning the insertion torque of implants placed and the cortical thickness measurements of the sheep's ilia was discussed.

Keywords: Dental Implant; Ovine; Sheep; Insertion Torque.

\section{Introduction}

"For a large number of problems there will be some animal of choice, or a few such animals, in which it can be most conveniently studied" - Quoted by August Krogh in 1929 [1].

Research in the development of new orthopedic or dental implant systems has always required extensive in vitro and in vivo studies. Numerous animal models have been described and utilized in literature. These included: pig, dog, sheep, goat, rat, guinea pig, chicken, and mice [2-7]. These animal models differ with respect to: anatomical limitations, biologic acceptability of certain materials, availability of the animals, and ethical considerations. Further- more, there is a definite need to articulate appropriate criteria for the selection of animal models. These criteria should focus on how to effectively translate certain research elements into appropriate animal models that most reliably translate to both human and animal benefit [1]. This can lead to creating sound hypotheses that can accurately reflect on human models.

The bone placement surface should be anatomically and surgically accessible with the least morbidity, should be large enough to accommodate and optimize the number of dental implants placed and provide bone of acceptable density to ensure ideal insertion torque and primary stability of the dental implants.

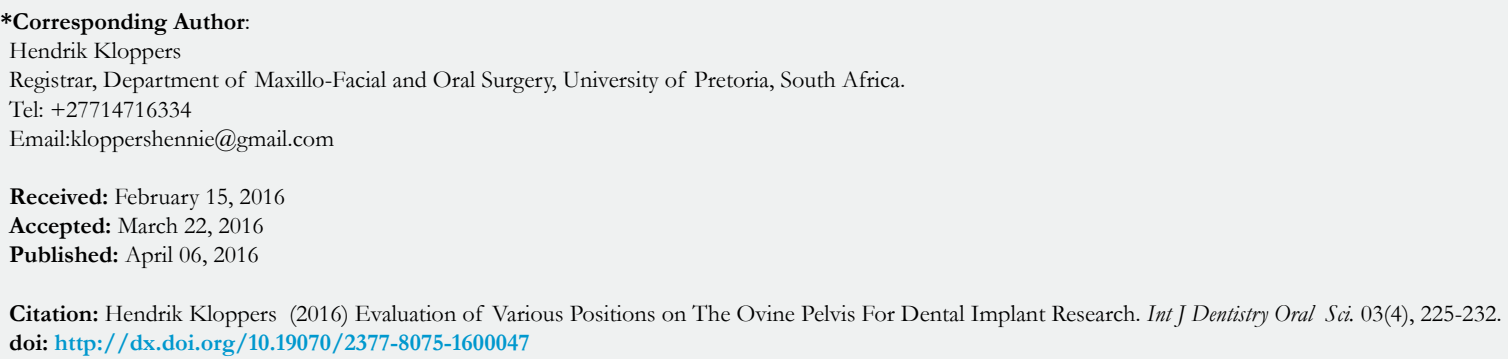

Copyright: Hendrik Kloppers ${ }^{\circ}$ 2016. This is an open-access article distributed under the terms of the Creative Commons Attribution License, which permits unrestricted use, distribution and reproduction in any medium, provided the original author and source are credited. 


\section{Subjects and Methods}

\section{Dental Implants}

Ninety-six ( $\mathrm{n}=96)$ titanium dental implants of identical length and diameter (Southern Implants, South Africa) were used. The implants were titanium, tapered implants, $4 \mathrm{~mm}$ in diameter, and $10 \mathrm{~mm}$ in length (IBT-10, Southern Implants, South Africa). The implants were divided into four groups of 24 implants. Twentyfour implants were allocated to each experimental animal, divided equally between two pelvi, 12 per side.

\section{Sheep}

Four adult, non-gestating, non-lactating, female sheep of the same average weight (49-87kg) were used as experimental animals. All animals were provided by the Onderstepoort Research Centre (University of Pretoria, South Africa).

\section{Torque wrench}

Insertion torque was measured using a calibrated, hand-driven torque wrench (Southern Implants, South Africa).

\section{Surgical drill unit}

An electrical surgical drill unit (W\&H, Germany) was used to prepare pilot holes, as well as osteotomy sites prior to the insertion of the implants.

\section{Implant drill set}

A standardised implant drill set (Southern Implants) was used to prepare the osteotomy sites.

Surgery was performed in an operative theatre at the Faculty of Veterinary Science, Onderstepoort Campus, University of Pretoria. Preoperative medication, general anaesthesia and surgery were performed by qualified veterinary surgeons, with surgical assistance by H.P. Kloppers.

The first experimental animal was placed in lateral recumbence and turned to gain surgical access to the opposite hip as suggested in the literature $[3,9]$. The remaining three sheep were placed in a prone, supine position with abdominal support (Figure 1) and endotrachealy intubated to provide maintenance anaesthesia and prevent aspiration of rumen contents, as was experienced with the first animal in lateral recumbence. This provided direct access to both sides of the animal, without the need to turn the animal intra-operatively. This operating position also avoided unnecessary pressure on the completed side while surgery on the second hip was performed.

Induction and maintenance anaesthesia was performed in the following manner:

- Sedation with intravenous Medetomidine ( $5 \mu \mathrm{g} / \mathrm{kg})$.

- Induction of general anaesthesia using Ketamine $(92 \mathrm{mg} / \mathrm{kg})$ and Diazepam $(0.01 \mathrm{mg} / \mathrm{kg})$.

- Maintenance anaesthesia was provided with $0.8 \%$ Isoflurane and Oxygen, and intravenous Ketamine $(60 \mathrm{mg} / \mathrm{ml})$ at a rate of $10 \mathrm{ml} / \mathrm{kg} / \mathrm{h}$.
- Fluid maintenance with Lactated Ringers.

- Antibiotic prophylaxis consisting of 30,000 IU $/ \mathrm{kg}$ Penicillin and $6 \mathrm{mg} / \mathrm{kg}$ Gentamycin intravenously every eight hours intra-operatively.

- 500 Units of equine tetanus as a single dose was administered subcutaneously.

Wool was shaved over the surgical area and skin and surrounding surgical field disinfected with 10\% Povidone Iodine (Dismed Pharma, Midrand, South Africa).

Surgical approach termed a caudal roll-up (as described by the veterinary surgeon, Dr. M. Hartman, Onderstepoort, University of Pretoria) was performed to allow exposure of the iliac crest and the linea glutea. The technique comprised an incision through the skin on the lateral surface of the leg of the sheep. In this way, the muscles of the posterior limb were exposed (Figure 2), which was followed by an incision through the tensor fasciae latae and gluteobiceps muscles. An upward roll of the mobilized soft tissues finally exposed the ilium (Figure 3).

Pilot holes for the implants were drilled on the lateral surface of the ilium, dorsal and ventral to the linea glutea. Six holes were drilled on the dorsal and ventral sides, respectively. These holes were prepared to correspond with a line $5 \mathrm{~mm}$ off the ridge of the linea glutea with the most cranially positioned implants $10 \mathrm{~mm}$ caudal to the anterior crest of the greater wing of the ilium (Figure $4 \mathrm{~A}$ and $\mathrm{B})$.

The dorsal and ventral groups of pilot holes were positioned $10 \mathrm{~mm}$ apart, starting at a point measured $10 \mathrm{~mm}$ form the greater wing of the ilium. These positions were determined ex-vivo on dry osteology specimens, starting $10 \mathrm{~mm}$ from the greatest curvature of the iliac wing cranially. Implant sites were spaced caudally, $10 \mathrm{~mm}$ apart, on either side of the linea glutea. It was possible to place six implants on the dorsal surface of the shaft and six implants on the ventral surface of the shaft. These six positions from cranial to caudal were labelled position A, B, C, D, E, F (Figure 4 B).

Implant osteotomy sites were created by drilling through the outer cortex using a round drill (D-RM-MS, Southern Implants, South Africa) followed by a twist drill with a diameter of $2 \mathrm{~mm}$ (D20-T, Southern Implants, South Africa). Final osteotomy sites were prepared up to a length of $10 \mathrm{~mm}$ using the finishing drill (D-40TP-10, Southern implants, South Africa). All holes were drilled at a speed of 1500 revolutions per minute (RPM) with copious amounts of sodium chloride $(0.9 \%)$ irrigation (Figure 5$)$.

Twelve IBT 10mm dental implants (Southern Implants, South Africa) were inserted in each ilium, adding to a total of 24 implants per animal. All implants were inserted up to a level where the external hexed implant platform was level with the surrounding bone. The final insertion torque was measured using the calibrated torque wrench (Southern Implants, South Africa) (Figure 6).

Surgical wounds were sutured by the veterinary surgeon using 3.0 Vicryl and 3.0 Nylon (Ethicon, Johnson \& Johnson Inc.). Wounds were closed in layers to prevent hematoma formation, and to ensure approximation of all muscles. 
Two of the animals were euthanized at weeks two and four, respectively. The implants were exposed and the removal torque of each implant was measured using the calibrated torque wrench.

The pelvi were harvested from the euthanized animals by the veterinary surgeon and labelled for further evaluation in a research laboratory.

The harvested pelvi were sectioned coronally using a diamondcutting wheel at the predetermined positions (Figure 7). The cortical thickness of each section was measured using a calibrated micrometer. Measurements were taken at the dorsal and ventral osteotomy sites, at the same angle that the dental implants were placed at. All measurements were documented and charted for comparison with the insertion torque values.

\section{Discussion}

The experimental design for this study was an animal model in the ovine iliac shaft. This model has previously been used to investigate the osseointegration properties of various implant designs [9]. The ovine model is well established in orthopaedic and biomedical research $[1-5,10]$. The similarity in lamellar bone structure to humans has made this model common in research involving fracture healing, osteosynthesis techniques and implant osseointegration $[3,21,22]$. There is a close resemblance between bone from the sheep pelvic region and the human mandible. There is more cancellous structure in the cranial part of the ilium, with increasing cortical thickness toward the caudal part. Lekholm and Zarb published similar findings, in which they mentioned that the osteology of the sheep ilium is similar to that found in humans $[11]$.

Apart from the physiological suitability, sheep are easy and relatively inexpensive to procure and handle peri-operatively. The first experimental animal was placed in lateral recumbence and turned to gain surgical access to the opposite hip as suggested in the literature $[3,9]$. The remaining three sheep were placed in a prone, supine position with abdominal support (Figure 1). The potential for accidental extubation during turning and aspiration of rumen content was, therefore, minimized. Both the non weight-bearing characteristics of the ovine ilium, and our supine surgical positioning contributed to the low morbidity, which was evident in the lack of interference with normal ambulation post-operatively.

The novel caudal roll-up technique allowed for maximal exposure of the linea glutea. This exposure allowed for ideal implant angulation, reducing the need for excessive muscle and soft tissue stripping. In addition, this contributed to the low surgical morbidity.

The principal advantage of the pelvic model was the ability to compare multiple implants, in several positions (i.e. 12 per ilium), within a single animal. This allowed for a reduction in interanimal variability. The predetermined dental implant positions allowed for insertion torque values that corresponded with values for primary stability $(32-35 \mathrm{Ncm})$.

Figure 1. Positioning of the sheep.

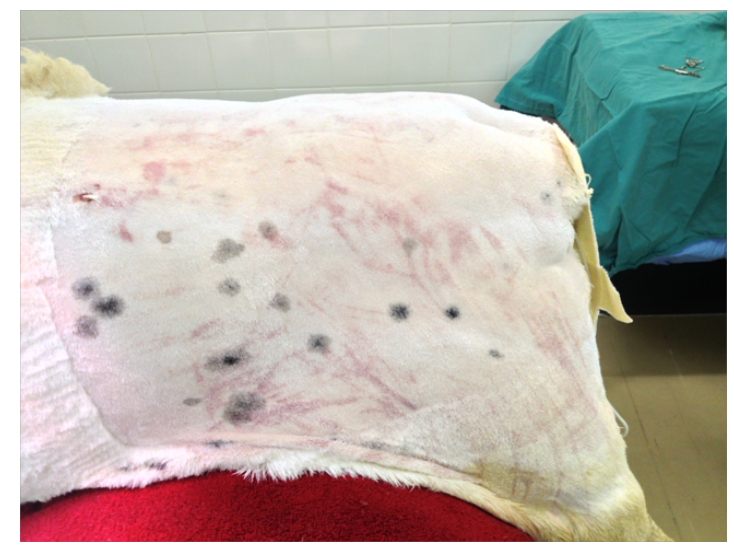

Figure 2. Caudal roll up surgical exposure of the ilium.

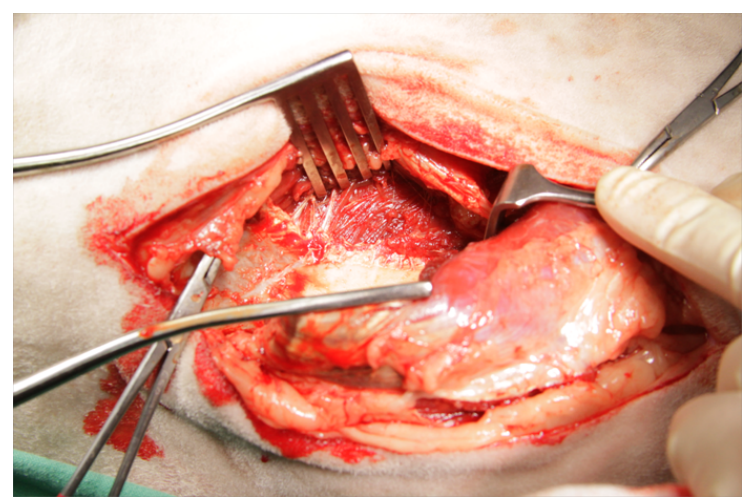


If an implant achieved an insertion torque in the range of 32-35 $\mathrm{Ncm}$, it was considered to be a successful implant with sufficient primary stability. Off the 96 implants placed, eight $(8.33 \%)$ failed to achieve an insertion torque of above $32 \mathrm{Ncm}$. Two implants $(2.08 \%)$, both on the ventral surface in position $\mathrm{F}$, were lost due to mechanical and technique complications at time of placement. On both these implants, the internal connection of the placement fixture failed due to excessive torque.

In a study by Miyamoto (2005) [23] the mean cortical thickness measurements observed for the mandible and maxilla were $2.22 \mathrm{~mm}$ and $1.49 \mathrm{~mm}$, respectively. Comparable results were found in the present ovine model. A minimum cortical thickness at position $A$ of $\geq 2 \mathrm{~mm}$ for both dorsal and ventral positions $(2.43 ; 2.05)$ was observed. In addition, a progressive increase in cortical thickness from positions $A$ through $F$ (dorsal and ventral) was found. Cortical measurements at every position $(A-F)$ on the dorsal side of the ilium were consistently greater than their ventral counterparts. A gradual increase $(2.05-2.80 \mathrm{~mm})$ in cortical thickness on the ventral side, compared to the more acute increase $(2.43-4.04 \mathrm{~mm})$ on the dorsal side was observed. (Figure $8 \mathrm{~A}$ ). The mean IT for implants at position A on the dorsal and ventral sides were $30.75 \mathrm{Ncm}$ and $44.00 \mathrm{Ncm}$, respectively. At the most caudal position $(\mathrm{F})$, average IT was $68.00 \mathrm{Ncm}$ and
$48.75 \mathrm{Ncm}$. A gradual increase in IT on both dorsal and ventral sides was observed. Multiple experimental studies have concluded IT values close to the range of $32-35 \mathrm{Ncm}$ to be satisfactory [1719]. Implants at position $A$ on the ventral side might, therefore, be considered as less than ideal (Figure 8B). With the progressive placement of implants in a cranio-caudal direction (for both dorsal and ventral sides), an increase in cortical thickness resulted in an increase in IT at the corresponding positions (Figure 8A - B).

Bone quality is broken down into four groups, according to the proportion and structure of compact and trabecular bone mass [24]. The quality of bone gets categorized into: groups Type I to IV (Bone Quality Index - BQI). Type I consists of homogenous compact bone throughout the entire jaw; Type II bone consists of a dense core of trabecular bone surrounded by a thick layer of compact bone; Type III bone consists of a dense core of trabecular bone, surrounded by only a thin layer of cortical bone and Type IV bone is comprised of a thin layer of cortical bone surrounding low-density trabecular bone [11]. The average cortical thickness values observed in this study were comparable with the average values as referenced by Miyamoto (2005) [23]. Bone quality in the ovine ilium may, therefore, be regarded as consistent with Type I and Type II bone.

Figure 3. Exposure of the ilium.

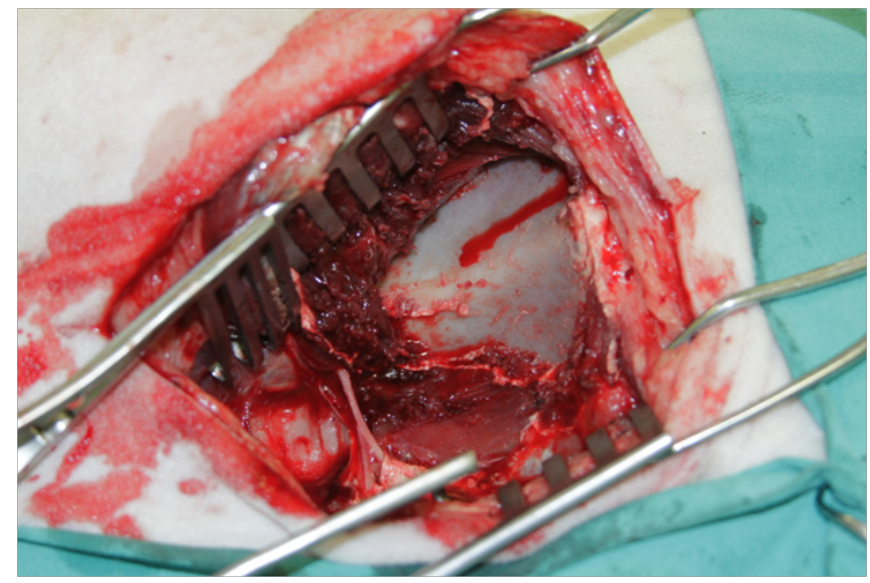

Figure 4 A-B. Pilot holes on dorsal and ventral sides of the ilium, positioned $10 \mathrm{~mm}$ apart.
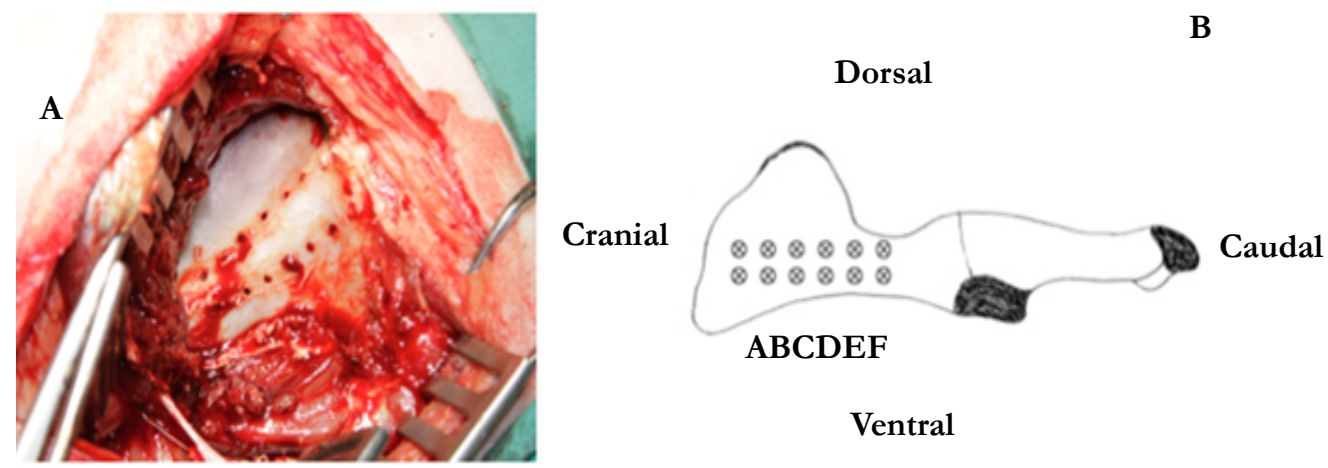

Ventral 
Figure 5. Implant osteotomy sites prepared.

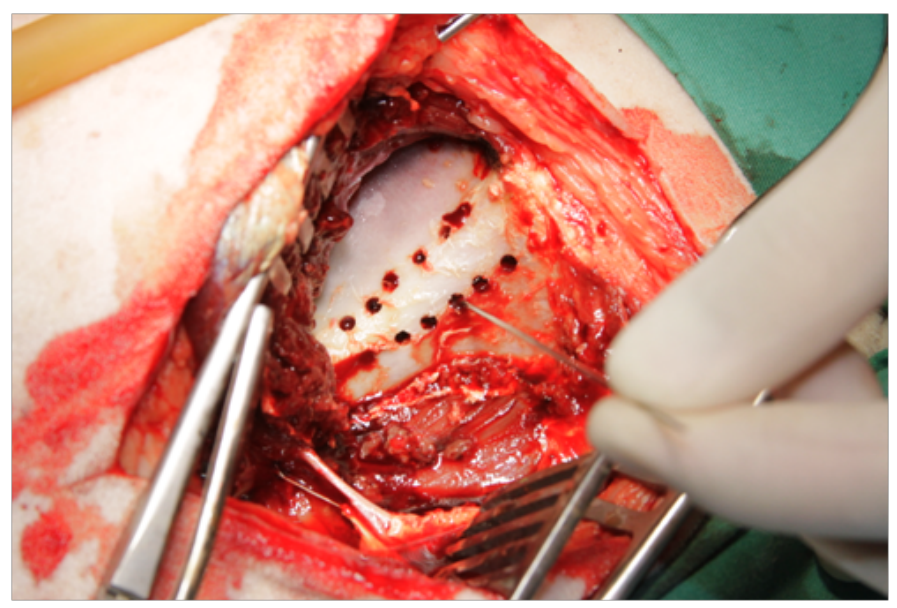

Figure 6. Final inserted implants.

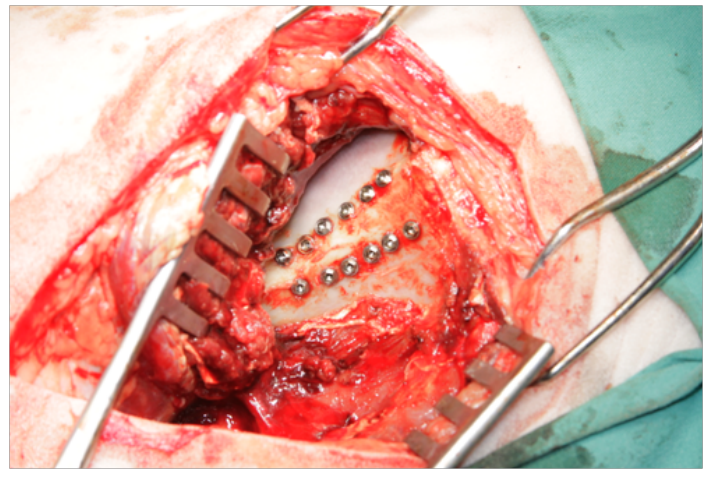

Figure 7. Coronal sections.

\section{Medial}

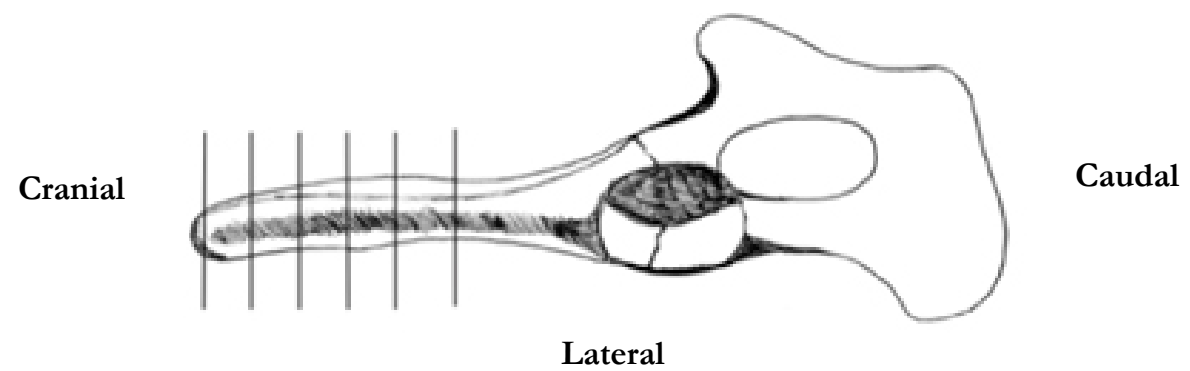

Figure 8A. Average dorsal and ventral cortical thickness.

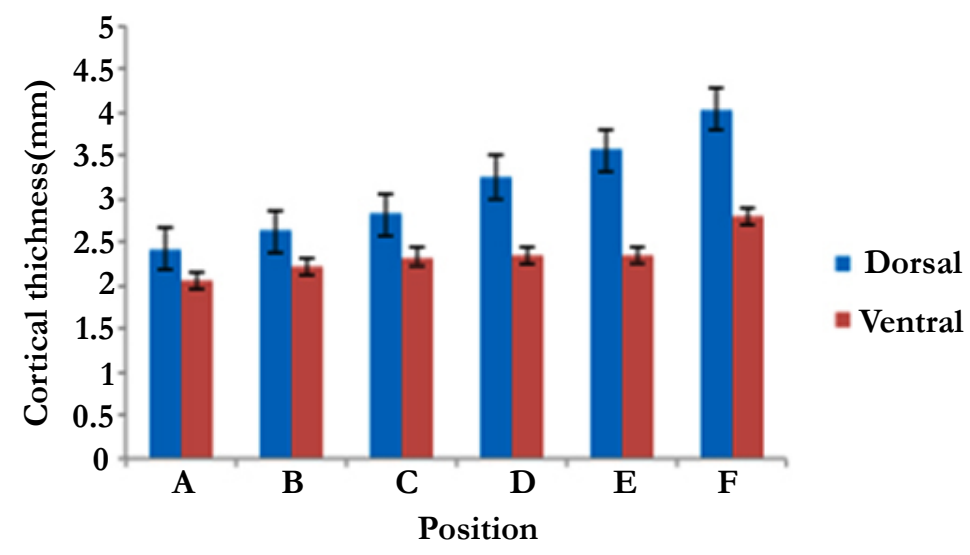


Figure 8B. Average dorsal and ventral insertion torque.

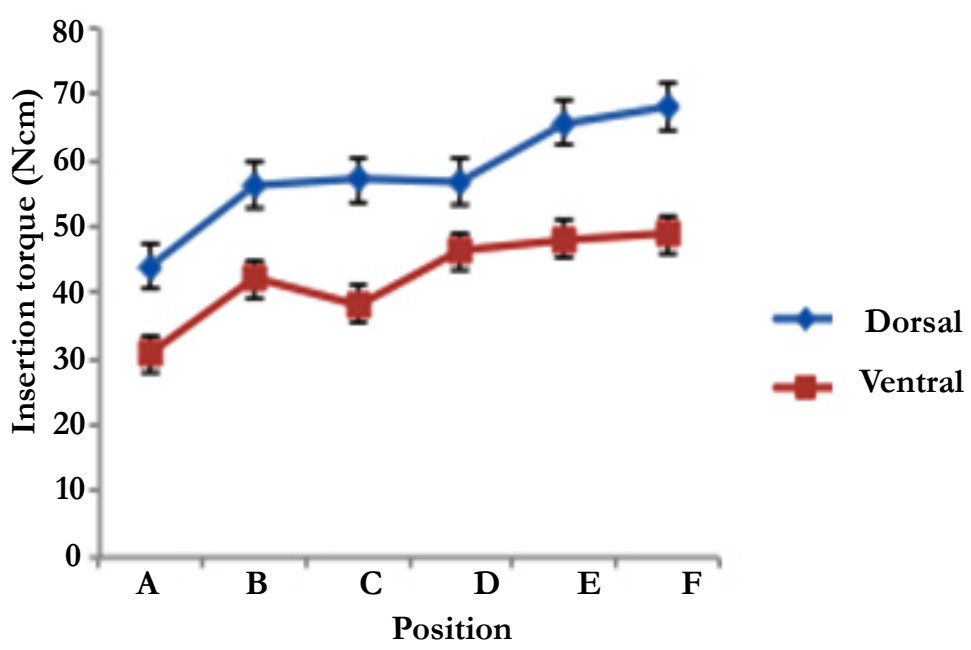

\section{Results}

- Based on the fact that this is a descriptive study with consideration of:

- Implant position based on anatomical determining of implant placement sites on the ilium of the animal model.

- The development of a unique, minimally invasive surgical procedure/technique (caudal roll-up) to gain access to the ilium to maximize the amount of implants placed for each ilium.

Evaluation of perioperative anaesthetic related issues in order to achieve optimum results in the ovine osseo-integration experimental model. The results will be expressed based on a successful outcome, without the use sample size, P-values, or T-testing.

Table 1: Insertion torque values (Sheep 1 left and right).

\begin{tabular}{|l|l|l|l|l|l|}
\hline \multicolumn{6}{|l|}{ Sheep 1 - Right } \\
\hline Dorsal \\
\hline A & B & C & D & E & F \\
\hline 52 & 48 & 56 & 78 & 72 & 78 \\
\hline 46 & 52 & 52 & 58 & 52 & 78 \\
\hline A & B & C & D & E & F \\
\hline Ventral &
\end{tabular}

\begin{tabular}{|l|l|l|l|l|l|}
\hline \multicolumn{6}{|l|}{ Sheep 1 - Left } \\
\hline Dorsal \\
\hline A & B & C & D & E & F \\
\hline 36 & 72 & 88 & 58 & 84 & 52 \\
\hline 38 & 46 & 52 & 52 & 38 & 46 \\
\hline A & B & C & D & E & F \\
\hline Ventral
\end{tabular}

\section{Conclusions}

Intraoral dental implant research in animals is challenging, owing in particular to different tooth morphology. One of the most challenging problems with intraoral implant research in animals is an infection form contaminated oral cavity, which is evident in intraoral research related to pigs and dogs [8]. Intraoral dental implant studies by Vlaminck confirmed that the specific oral biomechanics inherent to a sheep's constant ruminant activity accounted for high degrees of implant failures [13, 25].
The novel caudal roll-up exposure limited surgical morbidity to a minimum. In addition, the versatility of the sheep model contributed to successful experimentation. The cortical thickness and IT measurements provide a reference for future studies in dental implant research (i.e. dental implant design and osseointegration). We, therefore, conclude that the ovine pelvis is an ideal model for future dental implant research. 
Table 2: Insertion torque values (Sheep 2 left and right).

\begin{tabular}{|c|c|c|c|c|c|}
\hline \multicolumn{6}{|c|}{ Sheep 2 - Right } \\
\hline \multicolumn{6}{|c|}{ Dorsal } \\
\hline A & B & $\mathrm{C}$ & $\mathrm{D}$ & $E$ & $\mathrm{~F}$ \\
\hline 34 & 34 & 44 & 58 & 62 & 80 \\
\hline 28 & 22 & 32 & 44 & 40 & 60 \\
\hline A & B & $\mathrm{C}$ & $\mathrm{D}$ & $E$ & $\mathrm{~F}$ \\
\hline
\end{tabular}

\begin{tabular}{|c|c|c|c|c|c|}
\hline \multicolumn{6}{|c|}{ Sheep 2 - Left } \\
\hline \multicolumn{6}{|c|}{ Dorsal } \\
\hline A & $\mathrm{B}$ & C & $\mathrm{D}$ & $\mathrm{E}$ & $\mathrm{F}$ \\
\hline 58 & 64 & 64 & 84 & 84 & 88 \\
\hline 42 & 52 & 15 & 64 & 36 & 50 \\
\hline A & B & $\mathrm{C}$ & $\mathrm{D}$ & $\mathrm{E}$ & $\mathrm{F}$ \\
\hline
\end{tabular}

Table 3: Insertion torque values (Sheep 3 left and right).

\begin{tabular}{|l|l|l|l|l|l|}
\hline \multicolumn{6}{|l|}{ Sheep 3 - Right } \\
\hline Dorsal \\
\hline A & B & C & D & E & F \\
\hline 74 & 84 & 60 & 52 & 68 & 88 \\
\hline 15 & 50 & 44 & 40 & 56 & Lost \\
\hline A & B & C & D & E & F \\
\hline Ventral
\end{tabular}

\begin{tabular}{|l|l|l|l|l|l|}
\hline \multicolumn{6}{|l|}{ Sheep 3 - Left } \\
\hline Dorsal \\
\hline A & B & C & D & E & F \\
\hline 22 & 60 & 52 & 46 & 74 & 80 \\
\hline 34 & 50 & 40 & 38 & 58 & 88 \\
\hline A & B & C & D & E & F \\
\hline Ventral
\end{tabular}

Table 4: Insertion torque values (Sheep 4 left and right).

\begin{tabular}{|c|c|c|c|c|c|}
\hline \multicolumn{6}{|c|}{ Sheep 4 - Right } \\
\hline \multicolumn{6}{|c|}{ Dorsal } \\
\hline $\mathrm{A}$ & $\mathrm{B}$ & $\mathrm{C}$ & $\mathrm{D}$ & $E$ & $\mathrm{~F}$ \\
\hline 44 & 48 & 52 & 44 & 42 & 46 \\
\hline 28 & 34 & 36 & 42 & 62 & Lost \\
\hline $\mathrm{A}$ & $\mathrm{B}$ & $\mathrm{C}$ & $\mathrm{D}$ & $E$ & $\mathrm{~F}$ \\
\hline
\end{tabular}

\begin{tabular}{|c|c|c|c|c|c|}
\hline \multicolumn{6}{|c|}{ Sheep 4 - Left } \\
\hline \multicolumn{6}{|c|}{ Dorsal } \\
\hline A & $\mathrm{B}$ & $\mathrm{C}$ & $\mathrm{D}$ & $\mathrm{E}$ & $\mathrm{F}$ \\
\hline 32 & 40 & 40 & 34 & 40 & 32 \\
\hline 15 & 30 & 34 & 32 & 42 & 68 \\
\hline A & $\mathrm{B}$ & $\mathrm{C}$ & $\mathrm{D}$ & $\mathrm{E}$ & $\mathrm{F}$ \\
\hline
\end{tabular}




\section{References}

[1]. Auer JA, Goodship A, Arnoczky S, Pearce S, Price J, et al. (2007) Refining animal models in fracture research: seeking consensus in optimising both animal welfare and scientific validity for appropriate biomedical use. BMC musculoskelet Disord 8:72.

[2]. Aerssens J, Boonen S, Lowet G, Dequeker J (1998) Interspecies differences in bone composition, density, and quality: potential implications for in vivo bone research. Endocrinology 139(2): 663-670.

[3]. Martini L, Fini M, Giavaresi G, Giardino R (2001) Sheep model in orthopedic research: a literature review. Comp Med 51(4): 292-299.

[4]. Neyt JG, Buckwalter JA, Carroll NC (1998) Use of animal models in musculoskeletal research. Iowa Orthop J 18: 118-123.

[5]. Nuss KM, Auer JA, Boos A, von Rechenberg B (2006) An animal model in sheep for biocompatibility testing of biomaterials in cancellous bones. BMC musculoskelet Disord 7: 67.

[6]. Pearce AI, Richards RG, Milz S, Schneider E, Pearce SG (2007) Animal models for implant biomaterial research in bone: a review. Eur Cell Mater 13: 1-10.

[7]. Ravaglioli A, Krajewski A, Celotti GC, Piancastelli A, Bacchini B, et al. (1996) Mineral evolution of bone. Biomaterials 17(6): 617-622.

[8]. Abrahamsson I, Zitzmann NU, Berglundh T, Wennerberg A, Lindhe J (2001) Bone and soft tissue integration to titanium implants with different surface topography: an experimental study in the dog. Int J Oral Maxillofac Implants 16(3): 323-332.

[9]. Langhoff JD, Voelter K, Scharnweber D, Schnabelrauch M, Schlottig F, et al. (2008) Comparison of chemically and pharmaceutically modified titanium and zirconia implant surfaces in dentistry: a study in sheep. Int J Oral Maxillofac Surg 37(12): 1125-1132.

[10]. Den Boer FC, Patka P, Bakker FC, Wippermann BW, van Lingen A, et al. (1999) New segmental long bone defect model in sheep: quantitative analysis of healing with dual energy x-ray absorptiometry. J Orthop Res 17(5): 654-660.

[11]. Lekholm U, Zarb GA (1985) Patient selection and preparation. In Tissueintegrated prostheses: osseointegration in clinical dentistry. Quintessence Publishing Co, Inc, Chicago. 199-209.

[12]. Guelph Uo. Animal and Poultry Science Ontario: University of Guelph; 2012. Available from: http://www.aps.uoguelph.ca.

[13]. May ND (1970) The Anatomy of the Sheep: a dissection manual. University of Queensland Press, St. Lucia, Australia. 3.
[14]. Branemark PI (1983) Osseointegration and its experimental background. J Prosthet Dent 50(3): 399-410.

[15]. Cehreli MC, Karasoy D, Akca K, Eckert SE (2009) Meta-analysis of methods used to assess implant stability. Int J Oral Maxillofac Implants 24(6): 1015-1032.

[16]. Nedir R, Bischof M, Szmukler-Moncler S, Bernard JP, Samson J (2004) Predicting osseointegration by means of implant primary stability. Clin Oral Implants Res 15(5): 520-528.

[17]. Turkyilmaz I, McGlumphy EA (2008) Influence of bone density on implant stability parameters and implant success: a retrospective clinical study. BMC oral health 8: 32.

18]. Da Cunha HA, Francischone CE, Filho HN, de Oliveira RC (2004) A comparison between cutting torque and resonance frequency in the assessment of primary stability and final torque capacity of standard and TiUnite singletooth implants under immediate loading. Int J Oral Maxillofac Implants 19(4): 578-585.

[19]. Horwitz J, Zuabi O, Peled M, Machtei EE (2007) Immediate and delayed restoration of dental implants in periodontally susceptible patients: 1-year results. Int J Oral Maxillofac Implants 22(3): 423-429.

[20]. Ottoni JM, Oliveira ZF, Mansini R, Cabral AM (2005) Correlation between placement torque and survival of single-tooth implants. Int J Oral Maxillofac Implants 20(5): 769-776.

[21]. Apelt D, Theiss F, El-Warrak AO, Zlinszky K, Bettschart-Wolfisberger R, et al. (2004) In vivo behavior of three different injectable hydraulic calcium phosphate cements. Biomaterials 25(7-8): 1439-1451.

[22]. Kuttenberger JJ, Waibel A, Stubinger S, Werner M, Klasing M, et al. (2010) Bone healing of the sheep tibia shaft after carbon dioxide laser osteotomy: histological results. Lasers Med Sci 25(2): 239-249.

[23]. Miyamoto I, Tsuboi Y, Wada E, Suwa H, Iizuka T (2005) Influence of cortical bone thickness and implant length on implant stability at the time of surgery--clinical, prospective, biomechanical, and imaging study. Bone 37(6): 776-780.

[24]. Ribeiro-Rotta RF, Lindh C, Pereira AC, Rohlin M (2011) Ambiguity in bone tissue characteristics as presented in studies on dental implant planning and placement: a systematic review. Clin Oral Implants Res 22(8): 789-801.

[25]. Vlaminck L, Gorski T, Huys L, Saunders J, Schacht E, et al. (2008) Immediate postextraction implant placement in sheep's mandibles: a pilot study. Implant Dent 17(4): 439-450. 